\title{
THE CHALLENGES IN IMPLEMENTING NUTRITION POLICY IN PAPUA NEW GUINEA
}

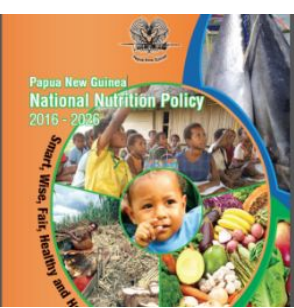

Helen Palik - 2018 WHO TDR Batch 3

\section{Trend of stunting}

The National Nutrition Survey 2005-2006, has shown that about $44 \%$ of the children from ages 6 -59 months in Papua New Guinea (PNG) are physically stunted, $5 \%$ are wasted and $18 \%$ are underweight. It also showed that $48 \%$ are anaemic, of which $28 \%$ have iron deficiency. The proportion of children with vitamin A deficiency accounted for $25.6 \%$ of the study population.

\section{- Fig.1 Stunting trends (\%) in PNG}

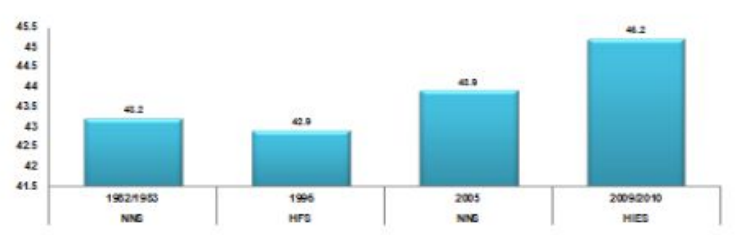

Goal: To improve nutrition for all Papua New Guineans through evidence-based, coordinated nutrition approaches that optimises resources and aligns actions.

Vision: A smart, fair, wise, healthy and happy nation through improved nutrition and health outcomes for all citizens of PNG.

Mission: To use multi-sectoral mechanisms to deliver comprehensive, integrated, equitable and sustainable approaches based on best practices, to improve health and nutrition outcomes for all Papua New Guineans.

\section{Challenge 1: Human resources}

Proportion of health workers to the population at lower level is inadequately distributed at the primary health care level and many times one staff is doing many things at the same time and there is often less focus to concentrate on one specific job to produce better expected results.

- $\quad$ Formula: Limited number of staff +many responsibilities + time=poor outcome

- Eg. MCH OIC is also caretaker of nutrition and Family planning services)

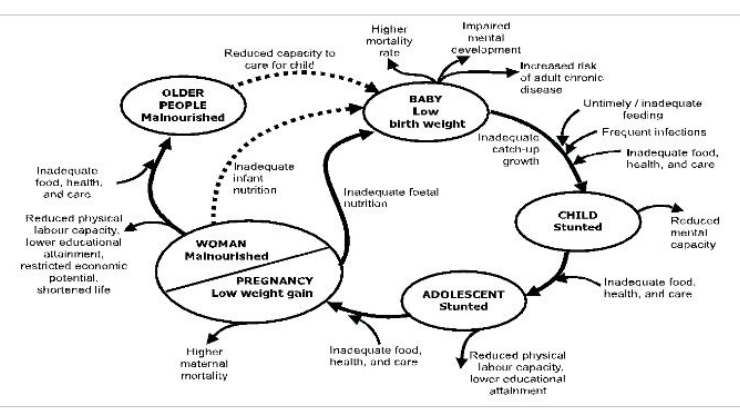

\section{Challenge 2: Local managers}

Many managers are working in difficult working conditions with changing environment and poor infrastructure, Managers face challenges in the areas of personal, technical performance, environment changes and survival and growth ,Shortell \& Kaluncy 2000) ,many of the managers do not know what exactly they are supposed to do.

- "Many challenges await. There are no panaceas for fixing our healthcare system".Shalala D1.
Many challenges experienced by policy implementers especially the managers at various levels of implementation. However these managers cannot be replaced with new ones, therefore more support and effort is needed to build their skills in management.

\section{Challenge 3: health system - need changes}

In PNG, there are many reasons why very good policies that have clear goals and visions are not implemented successfully as expected at all levels especially at the lower level where many of the outcomes are measured. Many blame the poor health system as a result of political influences while others have different opinions about various contributing factors including the WHO six building blocks which may have affected the policy implementation resulting in favourable or bad outcomes.

\section{Conclusion}

Strengthen M \& E system by the use of latest IT Technology (telemedicine) to asses outcomes and also monitors progress of policy implementation, capturing important indicators and /or interventions measured against the policies indicators, thus user friendly.

\section{References}

PNG National Health Plan 2011-2020; Don de Savigny: Systems thinking for health care system; S M Shortell: Suggestions for improving the study of health program implementation; Elliott S. Fisher etI WHO 2005 working paper 1-strengthening Health management in low income countries; Systems thinking in practice: the current status of the six WHO building blocks for health system strengthening in three BHOMA intervention districts of Zambia: a baseline qualitative study. Mutale $\mathrm{W}^{1}$, Bond $\underline{\mathrm{V}}$ Mwanamwenge MT, Mlewa S, Balabanova D, Spicer N, Ayles H.

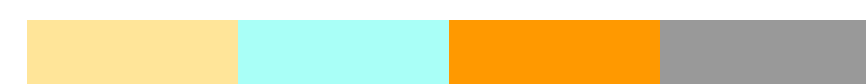

